\title{
Angiotensin II Type 1 Receptor Antagonism Attenuates Abnormalities in Dynamic Renal Blood Flow Autoregulation in Rats with Endotoxin-Induced Acute Kidney Injury
}

\author{
Nicoletta Nitescu ${ }^{a}$ Gerald F. DiBonac Elisabeth Grimberg ${ }^{b}$ Gregor Guron ${ }^{b}$ \\ ${ }^{a}$ Departments of Anesthesiology and Intensive Care, Institute of Clinical Sciences, and ${ }^{b}$ Department of Molecular \\ and Clinical Medicine/Nephrology, Institute of Medicine, University of Gothenburg, Gothenburg, Sweden; \\ ${ }^{c}$ Department of Internal Medicine, University of lowa College of Medicine, lowa City, lowa, USA
}

\section{Key Words}

Acute renal failure $\cdot$ Candesartan $\cdot$ Renal circulation .

Sepsis · Transfer function analysis

\begin{abstract}
Background: The aim was to examine the role of angiotensin II type 1 receptors in dynamic autoregulation of renal blood flow (RBF) in endotoxemia. Methods: Experiments were performed on anesthetized rats $16 \mathrm{~h}$ after intraperitoneal lipopolysaccharide (LPS) or vehicle administration. After baseline measurements, groups Sham-Saline, LPS-Saline and LPS-Candesartan received isotonic saline or candesar$\tan \left(10 \mu \mathrm{g} \mathrm{kg}^{-1}\right.$ i.v.). Data were collected during eight consecutive 20-min clearance periods (C1-8). Transfer function (TF) analysis in the frequency domain was used to examine dynamic autoregulation of RBF. Results: Endotoxemic rats showed an approximate $50 \%$ reduction in glomerular filtration rate (GFR) and RBF ( $p<0.05$ vs. Sham-Saline). Candesartan significantly increased RBF ( $+40 \pm 6 \%$ vs. baseline; $p<$ 0.05 ) but did not significantly influence GFR. Endotoxemic animals showed a normal myogenic response but had elevated TF gain values in the frequency range of the tubuloglomerular feedback mechanism (TGF; $0.01-0.03 \mathrm{~Hz}$ ) reflecting impaired autoregulation (periods $\mathrm{C} 3-4,2.2 \pm 1.6 \mathrm{vs}$. -2.6 $\pm 0.6 \mathrm{~dB}, \mathrm{p}<0.05$, and $\mathrm{C} 7-8,-0.4 \pm 1.3$ vs. $-4.0 \pm 0.8 \mathrm{~dB}$,
\end{abstract}

$p<0.05$; in groups LPS-Saline and Sham-Saline, respectively). Candesartan normalized TF gain in this frequency range (periods $C 7-8,-6.1 \pm 2.3 \mathrm{~dB}$ in group LPS-Candesartan, $p<0.05$ vs. LPS-Saline). Conclusion: Candesartan ameliorates the adverse effect of endotoxin on the TGF component of dynamic autoregulation of RBF.

Copyright $\odot 2010$ S. Karger AG, Basel

\section{Introduction}

Acute kidney injury (AKI) occurs in $20-50 \%$ of critically ill patients with sepsis and multiple organ dysfunction syndrome and is an independent risk factor contributing to the high mortality in this patient group [1]. Acute kidney injury in endotoxemia is characterized by marked renal vasoconstriction and reduced renal blood flow (RBF) $[1,2]$ that could at least partially be caused by an activation of the renin-angiotensin system (RAS) even when systemic arterial pressure (AP) is preserved $[2,3]$. Activation of the RAS has been demonstrated in both experimental [3, 4] and clinical [5] sepsis. In endotoxemia, the renal vasoconstrictor response to angiotensin II (Ang II), the main effector peptide of the RAS, is maintained [2] or enhanced [6], and could contribute to sepsis-induced AKI [1-3].

\section{KARGER}

Fax +41613061234 E-Mail karger@karger.ch www.karger.com

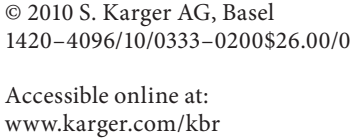


Autoregulation of RBF may be impaired during endotoxemia, although results are not conclusive $[7,8]$. Currently, RBF autoregulation is thought to be mediated mainly by the myogenic response (MR) and the tubuloglomerular feedback (TGF) mechanism [9]. It is possible that Ang II could modulate autoregulation of RBF during endotoxemia as previous studies have demonstrated that Ang II enhances TGF $[10,11]$ and perhaps also the MR [12]. We have previously demonstrated that a non-depressor dose of the angiotensin II type $1\left(\mathrm{AT}_{1}\right)$ receptor antagonist candesartan significantly improves the mean level of $\mathrm{RBF}$ and intrarenal $\mathrm{pO}_{2}$ in endotoxemic rats [13]. However, in that study [13], autoregulation of RBF was not assessed.

The aim of the present study was to examine whether dynamic autoregulation of RBF is impaired in endotoxemia, and if candesartan, administered in a non-depressor dose, could have beneficial effects on the autoregulatory response. For this purpose we applied transfer function (TF) analyses on spontaneous fluctuations in AP and $\mathrm{RBF}$, thereby enabling the analysis of the separate contributions of the MR and the TGF mechanism to dynamic autoregulation of RBF in anesthetized endotoxemic rats.

\section{Materials and Methods}

\section{General Procedures}

In brief, male Sprague-Dawley rats (Harlan, Horst, The Netherlands) weighing 260-310 g were used and all experiments were approved by the Regional Ethics Committee in Gothenburg. The protocol and experimental procedures have been described previously in detail [13]. TF analyses of RBF autoregulation were performed on a data material that to some extent has been previously analyzed for other purposes [13].

\section{Protocol}

Rats were divided into three study groups: (1) Sham-Saline $(\mathrm{n}=7),(2)$ LPS-Saline ( $\mathrm{n}=7)$, and (3) LPS-Candesartan $(\mathrm{n}=7)$. One animal with clearly outlying TF gain values in group LPSCandesartan was subsequently excluded by applying Peirce's criterion [14].

Endotoxemia was induced by administration of lipopolysaccharide (LPS) using a well-characterized model of sepsis in rats $[3,13]$. At 16 h of endotoxemia, rats were anesthetized with thiobutabarbital (Inactin; $120 \mathrm{mg} \mathrm{kg}^{-1}$ i.p.) and surgically prepared for renal clearance experiments as described [13]. A 45-min period was allowed for equilibration. After baseline measurements during two consecutive 20 -min clearance periods $(\mathrm{C} 1-\mathrm{C} 2)$, rats received either isotonic saline vehicle or the $\mathrm{AT}_{1}$ receptor antagonist candesartan in a bolus dose of $10 \mu \mathrm{g} \mathrm{kg}^{-1}\left(0.5 \mathrm{ml} \mathrm{kg}^{-1}\right)$ intravenously. This dose of candesartan has previously been shown not to decrease AP, but still to exhibit effective $\mathrm{AT}_{1}$ receptor blockade and to markedly attenuate the effects of Ang II bolus injections on AP and renal hemodynamics [15]. Control rats received an equivalent volume of isotonic saline. The effects of candesartan or saline were measured during six consecutive 20-min clearance periods $(\mathrm{C} 3-\mathrm{C} 8)$.

\section{Surgical Preparation and Measurements}

Rats were anesthetized and surgically prepared for renal clearance experiments as described $[13,16]$. A femoral arterial catheter was connected to a pressure transducer (Smiths Medical, Kirchseeon, Germany) for monitoring of AP (pulsatile and mean [MAP]) and heart rate using a data acquisition program (Biopac MP150; Biopac Systems, Santa Barbara, Calif., USA). A perivascular transit-time flow probe $(0.7$ VB, T206; Transonic Systems Inc., Ithaca, N.Y., USA) was placed around the left renal artery for measurement of RBF. Renal nerves were kept intact. Glomerular filtration rate (GFR) was determined by measuring renal ${ }^{51} \mathrm{Cr}$ EDTA clearance $\left({ }^{51} \mathrm{Cr}\right.$-ethylenediaminetetraacetic acid; Amersham Laboratories, Buckinghamshire, UK), as previously reported $[13,16]$. Rats were infused with $10 \mathrm{ml} \mathrm{kg}^{-1} \mathrm{~h}^{-1}$ of isotonic saline throughout the experiments. After the last clearance period, rats were euthanized by an overdose of pentobarbital sodium. Biochemical analyses and calculations were performed as described [13]. Filtration fraction was estimated as the ratio between GFR and renal plasma flow $(\mathrm{RBF} \times[1-$ hematocrit $])$.

\section{Transfer Function Analysis}

Data used to examine the dynamic relationship between AP and RBF, i.e. dynamic autoregulation of RBF, were digitally lowpass filtered $(10 \mathrm{~Hz})$ and sampled at $62.5 \mathrm{~Hz}$ yielding 75,000 data points for each 20 -min period. Processing of AP and RBF data was performed offline using previously developed software routines written for Matlab 7.14 (The MathWorks Inc., Natick, Mass., USA). Data files were detrended by removing the mean and then decimated to a rate of $6.25 \mathrm{~Hz}$. These $6.25-\mathrm{Hz}$ data files were split into blocks of 4,096 data points, yielding a frequency discrimination of $0.0015 \mathrm{~Hz}$. Power spectral density (PSD) of AP and RBF was calculated, as described $[17,18]$. The TF spectra were calculated from AP (input) and RBF (output). The TF gain was taken as the quotient of the cross-spectrum of input and output divided by the power spectrum of the input $[17,18]$. Coherence is a frequency domain estimate of a linear correlation (i.e. squared coherence, akin to coefficient of determination) between two signals indicating the degree to which the variance in one signal can be explained by a linear operation on the other signal $[17,18]$. The coherence spectra were calculated from AP (input) and RBF (output). The coherence function was taken as the quotient of the square of the cross-spectrum of input and output divided by the product of the power spectral densities of AP and RBF $[17,18]$. These algorithms involved a Hanning window with $50 \%$ overlap of the blocks. To permit comparison among rats, the TF gain (magnitude) values over the frequency range have been normalized to the mean value of the renal vascular conductance for the entire dataset. After conversion of the normalized TF gain values into decibels (20 log[gain]), a mean spectrum was calculated from the consecutive spectra in each rat, and these were subsequently averaged for all rats. The TF gain corresponds to the ratio of the amplitude of normalized fluctuations in RBF divided by those of AP. In the presence of autoregulation, fluctuations of RBF are attenuated versus those of AP causing the TF gain to be negative. 
Table 1. Baseline renal hemodynamics and excretory function prior to candesartan or vehicle administration

\begin{tabular}{|c|c|c|c|}
\hline & $\begin{array}{l}\text { Sham-Saline } \\
(\mathrm{n}=7)\end{array}$ & $\begin{array}{l}\text { LPS-Saline } \\
(\mathrm{n}=7)\end{array}$ & $\begin{array}{l}\text { LPS-Candesartan } \\
(\mathrm{n}=6)\end{array}$ \\
\hline MAP, $\mathrm{mm} \mathrm{Hg}$ & $115 \pm 1$ & $122 \pm 5$ & $122 \pm 3$ \\
\hline $\mathrm{HR}, \mathrm{bpm}$ & $376 \pm 7$ & $481 \pm 27^{*}$ & $482 \pm 13$ \\
\hline 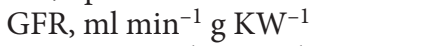 & $1.26 \pm 0.03$ & $0.61 \pm 0.03^{*}$ & $0.67 \pm 0.05$ \\
\hline $\mathrm{RBF}, \mathrm{ml} \mathrm{min} \mathrm{m}^{-1} \mathrm{gW}^{-1}$ & $8.3 \pm 0.5$ & $4.5 \pm 0.4^{*}$ & $4.5 \pm 0.4$ \\
\hline $\mathrm{RVR}, \mathrm{mm} \mathrm{Hg} \mathrm{ml} \mathrm{m}^{-1} \min ^{1} \mathrm{~g} \mathrm{KW}^{1}$ & $14.1 \pm 0.8$ & $28.2 \pm 2.7^{*}$ & $28.4 \pm 2.7$ \\
\hline $\mathrm{FF}, \%$ & $28.7 \pm 1.7$ & $24.7 \pm 1.6$ & $26.6 \pm 4.3$ \\
\hline 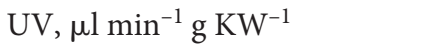 & $3.96 \pm 0.76$ & $2.52 \pm 0.09$ & $3.85 \pm 0.40$ \\
\hline $\mathrm{FE}_{\mathrm{Na}}, \%$ & $0.31 \pm 0.07$ & $0.24 \pm 0.05$ & $0.41 \pm 0.11$ \\
\hline $\mathrm{U}_{\mathrm{Na}} \mathrm{V}, \mu \mathrm{mol} \min ^{-1} \mathrm{~g} \mathrm{KW}^{-1}$ & $0.46 \pm 0.12$ & $0.15 \pm 0.03$ & $0.30 \pm 0.10$ \\
\hline
\end{tabular}

Baseline renal clearance data in thiobutabarbital anesthetized rats $16 \mathrm{~h}$ after LPS, or isotonic saline, administration (see Methods section). Values are means of the first two 20-min clearance periods prior to candesartan or vehicle injection.

MAP = Mean arterial pressure; $\mathrm{HR}=$ heart rate; $\mathrm{GFR}=$ glomerular filtration rate; $\mathrm{KW}=$ kidney weight; $\mathrm{RBF}=$ renal blood flow; $\mathrm{RVR}=$ renal vascular resistance; $\mathrm{FF}=$ filtration fraction; $\mathrm{UV}=$ urine flow rate; $\mathrm{FE}_{\mathrm{Na}}=$ fractional urinary sodium excretion, and $\mathrm{U}_{\mathrm{Na}} \mathrm{V}=$ urinary sodium excretion. Values are means \pm SEM. ${ }^{*} \mathrm{p}<0.05$ between groups LPS-Saline and Sham-Saline. There were no statistically significant differences between groups LPS-Candesartan and LPS-Saline.
Thus, positive TF gain values indicate impaired autoregulation [9]. Phase and coherence spectra were similarly calculated and averaged. Data over the range of frequencies for the MR (0.1-0.3 $\mathrm{Hz}$ ) and TGF (0.01-0.03) mechanisms as well as the complete dynamic response of MR and TGF $(<0.01 \mathrm{~Hz})$ were analyzed [9].

\section{Statistics}

Values are means \pm SEM. Presented baseline data are average values of the two clearance periods (C1-2) prior to candesartan or saline administration. Statistical analyses were performed by oneway analysis of variance (ANOVA), Student's unpaired t test, or ANOVA for repeated measurements, when appropriate. TF data were averaged for two consecutive clearance periods (i.e. C1-2, C3-4, C5-6 and C7-8) before statistical analyses between groups were carried out, in order to obtain stable baseline values and postintervention changes in TF gain. The following prespecified between-group analyses were performed: LPS-Saline versus ShamSaline, and LPS-Candesartan versus LPS-Saline. A value of $\mathrm{p}<$ 0.05 was considered statistically significant. The statistical software program SPSS 11.5.1 was used (SPSS Inc., Chicago, Ill., USA).

\section{Results}

\section{Baseline Hemodynamics and Kidney Function}

Baseline data prior to candesartan or vehicle administration are presented in table 1 . As previously reported [13], endotoxemic rats showed an approximate $50 \%$ decrease in GFR and RBF ( $p<0.05$ vs. Sham-Saline) although MAP did not differ significantly between groups (table 1). Filtration fraction, urine flow rate (UV), and absolute and fractional rates of urinary sodium and potassium (data not shown) excretion were not significantly different between groups (table 1).

\section{Effects of Candesartan on Hemodynamics and Kidney} Function in Endotoxemic Animals

In accord with previous results [13], candesartan increased RBF $(+40 \pm 6 \%$ vs. baseline; $p<0.05$ vs. LPSSaline) without significantly affecting MAP (fig. 1) and hence reduced renovascular resistance $(-33 \pm 3 \%$ vs. baseline; $\mathrm{p}<0.05$ vs. LPS-Saline). As described previously [13], candesartan had no significant effect on GFR but decreased filtration fraction (data not shown). Group LPS-Saline had a significantly reduced UV throughout C3-8, compared to Sham-Saline (LPS-Saline 3.04 \pm 0.17 vs. Sham-Saline $5.96 \pm 1.46 \mu \mathrm{l} \mathrm{min}^{-1} \mathrm{~g}$ kidney weight ${ }^{-1}$; $\mathrm{p}<0.05$ ), although absolute and fractional rates of urinary sodium excretion, and fractional urinary excretion of water, did not differ significantly between groups (data not shown). Group LPS-Candesartan demonstrated an increased UV throughout periods C3-8 (3.99 $\pm 0.31 \mu \mathrm{l}$ min $^{-1}$ g kidney weight ${ }^{-1}$ ) compared to LPS-Saline ( $\mathrm{p}<$ 0.05). However, in response to candesartan, endotoxemic rats demonstrated no significant changes in UV, or in absolute or fractional rates of urinary sodium excretion compared to baseline values (data not shown). 
Transfer Function Analyses, Effects of Endotoxin

Throughout C1-8 all study groups showed marked reductions in TF gain in the frequency range $0.1-0.3 \mathrm{~Hz}$ corresponding to the MR (fig. 2-4). Furthermore, there were no statistically significant differences between groups in TF gain values in this frequency interval indicating an intact MR in endotoxemic animals.

Endotoxin caused a significant increase in TF gain values, reflecting lack of efficient autoregulation of RBF, in the frequency range $0.01-0.03 \mathrm{~Hz}$ corresponding to the TGF mechanism, during experimental periods C3-4 (LPS-Saline $2.2 \pm 1.6$ vs. Sham-Saline $-2.6 \pm 0.6 \mathrm{~dB}$; $\mathrm{p}<0.05$; fig. 3) and C7-8 (LPS-Saline $-0.4 \pm 1.3$ vs. Sham-Saline $-4.0 \pm 0.8 \mathrm{~dB} ; \mathrm{p}<0.05$; fig. 4). During C1-2 gain, values were clearly positive in the frequency interval $0.01-0.03 \mathrm{~Hz}$ in group LPS-Saline and demonstrated a tendency to be elevated compared to Sham-Saline (3.0 \pm 2.5 vs. $-2.2 \pm 1.1 \mathrm{~dB} ; \mathrm{p}=0.084$; fig. 2 ).

At frequencies $<0.01 \mathrm{~Hz}$, corresponding to the complete dynamic response of both the MR and TGF, endotoxin increased TF gain during C3-4 (LPS-Saline $6.8 \pm$ 3.2 vs. Sham-Saline $-1.5 \pm 1.6 \mathrm{~dB}$; $\mathrm{p}<0.05$; fig. 3$)$ and C7-8 (LPS-Saline $3.3 \pm 1.8$ vs. Sham-Saline $-7.9 \pm 2.9$ $\mathrm{dB} ; \mathrm{p}<0.05$; fig. 4). During C1-2 TF, gain values were clearly positive in group LPS-Saline at frequencies $<0.01$ $\mathrm{Hz}$ and demonstrated a tendency to be elevated compared to Sham-Saline $(6.5 \pm 4.4$ vs. $-2.8 \pm 2.0 \mathrm{~dB} ; \mathrm{p}=0.078$; fig. 2).

There were no statistically significant differences between groups in PSD of AP or RBF in any of the abovementioned frequency intervals throughout periods $\mathrm{C} 1-8$ (fig. 2-4).

\section{Transfer Function Analyses, Effects of Candesartan}

Candesartan had no statistically significant effect on TF gain in the frequency range of the MR, i.e. $0.1-0.3 \mathrm{~Hz}$ (fig. 2-4). In the frequency range $0.01-0.03 \mathrm{~Hz}$, corresponding to the TGF mechanism, candesartan reduced, and normalized, TF gain values during C7-8 (-6.1 \pm 2.3 in group LPS-Candesartan vs. $-0.4 \pm 1.3 \mathrm{~dB}$ in group LPS-Saline; $\mathrm{p}<0.05$; fig. 4). At frequencies $<0.01 \mathrm{~Hz}$, candesartan significantly reduced TF gain during C5-6 $(-4.2 \pm 2.9$ in LPS-Candesartan vs. $5.9 \pm 2.9 \mathrm{~dB}$ in LPS Saline; $\mathrm{p}<0.05)$. In $\mathrm{C} 7-8 \mathrm{TF}$ gain was $-4.7 \pm 6.0 \mathrm{~dB}$ in group LPS-Candesartan and $3.3 \pm 1.8 \mathrm{~dB}$ in group LPSSaline ( $\mathrm{p}=0.20)$ at frequencies $<0.01 \mathrm{~Hz}$ (fig. 4). Candesartan had no statistically significant effects on the PSD of $\mathrm{AP}$ or RBF in any of the above-mentioned frequency intervals.

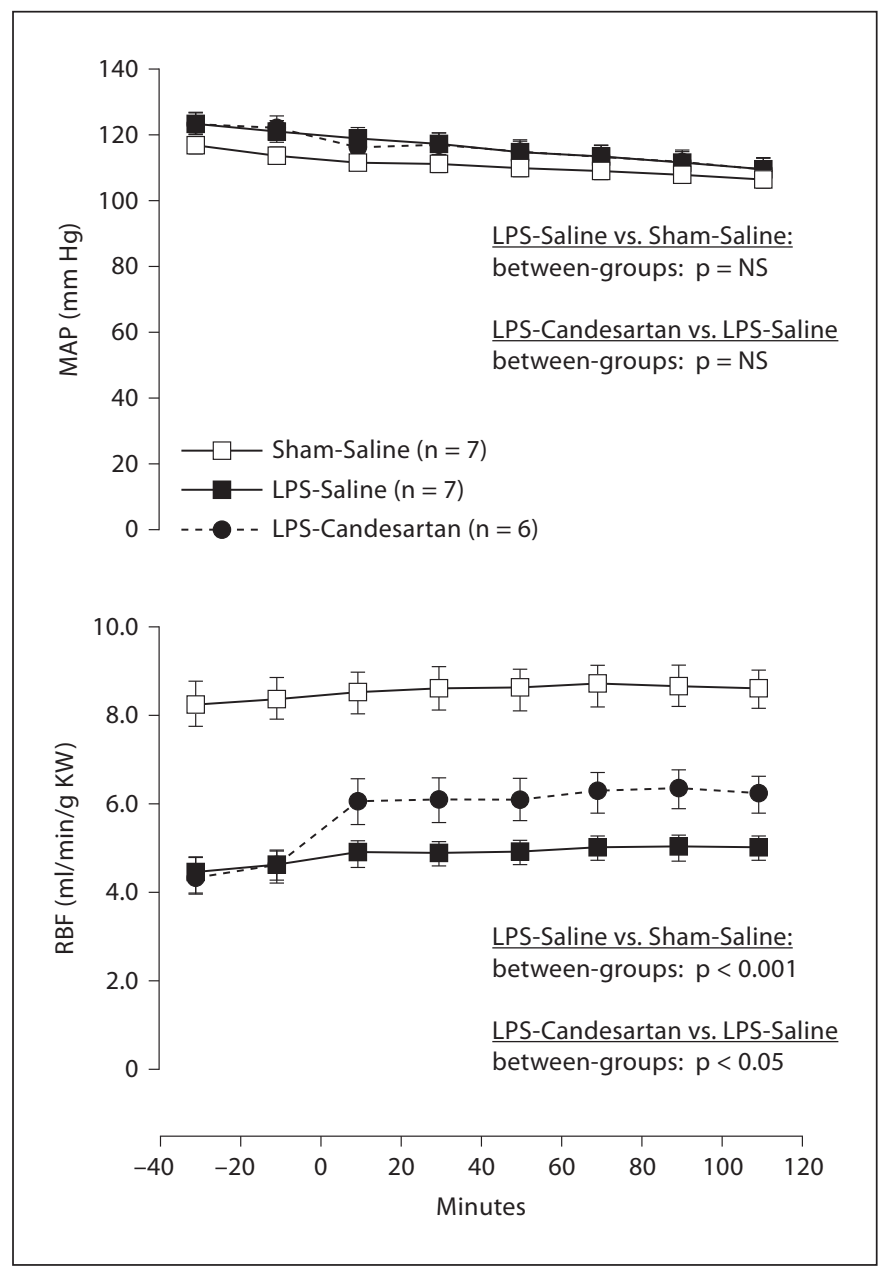

Fig. 1. Effect of candesartan $\left(10 \mu \mathrm{g} \mathrm{kg}^{-1}\right.$ i.v.) or isotonic saline on MAP and RBF in thiobutabarbital anesthetized rats, $16 \mathrm{~h}$ after LPS or isotonic saline vehicle administration. Candesartan or isotonic saline was administered at time $0 \mathrm{~min}$ (see Methods section). Values are means \pm SEM. Statistical analyses were performed by ANOVA for repeated measurements and $p$ values are for clearance periods 3-8 corresponding to time $0-120 \mathrm{~min}$. NS = Not statistically significant; KW = kidney weight.

\section{Discussion}

In the present study, endotoxemia impaired the TGF mechanism of RBF autoregulation. This was evident as significantly elevated TF gain values in group LPS-Saline compared to group Sham-Saline in the frequency interval $0.01-0.03 \mathrm{~Hz}$. In this situation, the $\mathrm{AT}_{1}$ receptor antagonist candesartan reduced TF gain values and 80-120 min after drug administration TF gain values were normalized in this frequency interval. The mechanisms by 
Fig. 2. PSD for AP and RBF, and TF gain, phase and coherence in thiobutabarbital anesthetized rats, $16 \mathrm{~h}$ after LPS or isotonic saline administration. Data are from baseline conditions during clearance period $\mathrm{C} 1$, i.e. prior to candesartan or vehicle administration. Transfer gain values showed similar, marked reductions in all groups in the frequency interval $0.1-0.3$ $\mathrm{Hz}$ corresponding to the MR. Note that gain values remained negative at frequencies below approximately $0.02 \mathrm{~Hz}$ in sham animals, whereas gain values were positive, reflecting impaired autoregulation in endotoxemic animals in the same frequency range. Statistical analyses were performed by Student's unpaired t test and are reported in the Results section. Values are means \pm SEM.

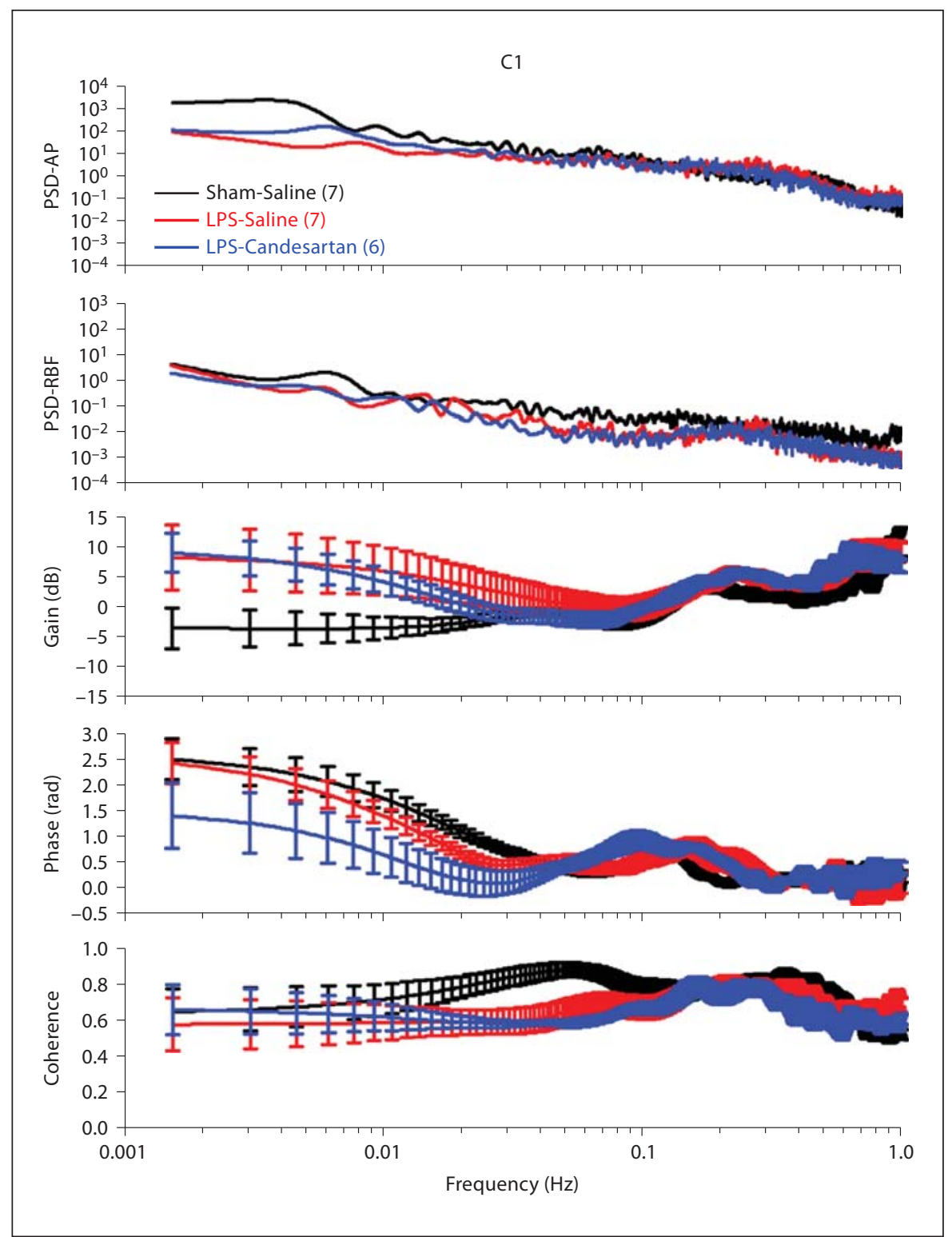

which endotoxemia attenuated the responsiveness of the TGF component of RBF autoregulation in the present study remain to be elucidated. One might speculate that endotoxemic animals had a decreased $\mathrm{NaCl}$ delivery to the macula densa (MD), as indicated by a reduced urinary flow rate, and that this would blunt the TGF mechanism. In line with this, it is possible that elevated intrarenal Ang II during endotoxemia could have increased proximal tubular $\mathrm{NaCl}$ reabsorption, resulting in decreased $\mathrm{MD} \mathrm{NaCl}$ delivery. In addition, GFR was reduced by approximately $50 \%$ in endotoxemic animals which would also indicate reduced distal $\mathrm{NaCl}$ delivery as a cause of a suppressed TGF response. However, neither absolute nor fractional urinary sodium excretion was significantly reduced in endotoxemic rats. Furthermore, although candesartan restored a normal TGF response in the present study, candesartan did not increase GFR, UV, or absolute or fractional urinary sodium excretion, suggesting that $\mathrm{AT}_{1}$ antagonism did not ameliorate the impaired TGF mechanism during endotoxemia by increasing distal $\mathrm{NaCl}$ delivery. Still, as we did not perform direct measurements of tubular flow rate or $\mathrm{NaCl}$ concentrations at the MD we cannot rule out that candesar$\tan$, at least partially, improved the TGF response in en- 
Fig. 3. PSD for AP and RBF, and TF gain, phase and coherence in thiobutabarbital anesthetized rats, $16 \mathrm{~h}$ after LPS or isotonic saline administration. Data are from clearance period C4 corresponding to 20 40 min after administration of candesartan or vehicle. Note that gain values remained negative at frequencies below approximately $0.02 \mathrm{~Hz}$ in sham animals, whereas gain values were positive, reflecting impaired autoregulation in endotoxemic animals in the same frequency range. Statistical analyses were performed by Student's unpaired t test and are reported in the Results section. Values are means \pm SEM.

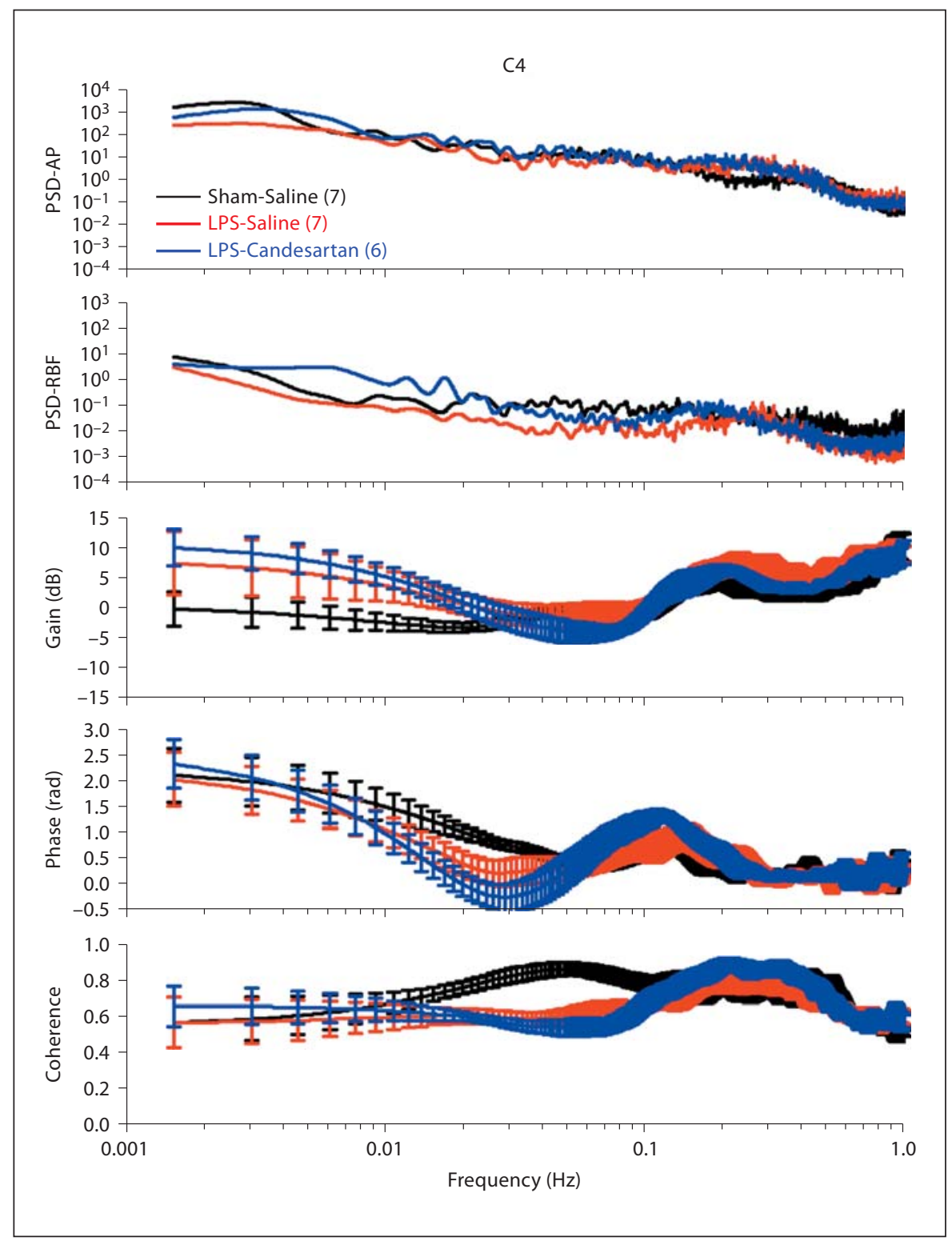

dotoxemic animals by increasing distal $\mathrm{NaCl}$ delivery. It may seem contradictory that candesartan improved the TGF mechanism in the present study as Ang II has been shown to enhance the TGF response, at least partially by stimulating $\mathrm{Na}-2 \mathrm{Cl}-\mathrm{K}$ cotransport activity in $\mathrm{MD}$ cells $[19,20]$. However, the effects of Ang II and candesartan on $\mathrm{MD} \mathrm{Na}-2 \mathrm{Cl}-\mathrm{K}$ cotransport activity are clearly dosedependent and while Ang II in concentrations of $10^{-9}$ and $10^{-12} \mathrm{M}$ increased $\mathrm{Na}-2 \mathrm{Cl}-\mathrm{K}$ cotransport activity, a higher concentration of $10^{-6} \mathrm{M}$ had no significant effect [20]. Thus, the effect of $\mathrm{AT}_{1}$ receptor antagonists on $\mathrm{MD} \mathrm{Na}-$ $2 \mathrm{Cl}-\mathrm{K}$ cotransport activity is likely to be highly variable and dependent on the prevailing local concentration of Ang II which would be expected to be high in endotoxemic animals in the present study.

A number of paracrine, hormonal and neural factors could have contributed to the impairment of the TGF mechanism in endotoxemic animals in the present study. For instance, endotoxin-induced increases in renal nitric oxide production could blunt the TGF mechanism [21, 22]. In addition, renal sympathetic nerve activity (RSNA) has been shown to be increased in endotoxemia $[1,3]$ and elevated RSNA could play a role. Previous results have shown that intensities of RSNA 
Fig. 4. $P S D$ for $A P$ and $R B F$, and $T F$ gain, phase and coherence in thiobutabarbital anesthetized rats, $16 \mathrm{~h}$ after LPS or isotonic saline administration. Data are from clearance period C7 corresponding to 80100 min after administration of candesartan or vehicle. Gain values remained negative at frequencies below approximately $0.02 \mathrm{~Hz}$ in group Sham-Saline, whereas gain values were positive, reflecting impaired autoregulation in group LPS-Saline in the same frequency range. Note that gain values were completely normalized in group LPS-Candesartan at frequencies below approximately $0.02 \mathrm{~Hz}$. Statistical analyses were performed by Student's unpaired t test and are reported in the Results section. Values are means \pm SEM.

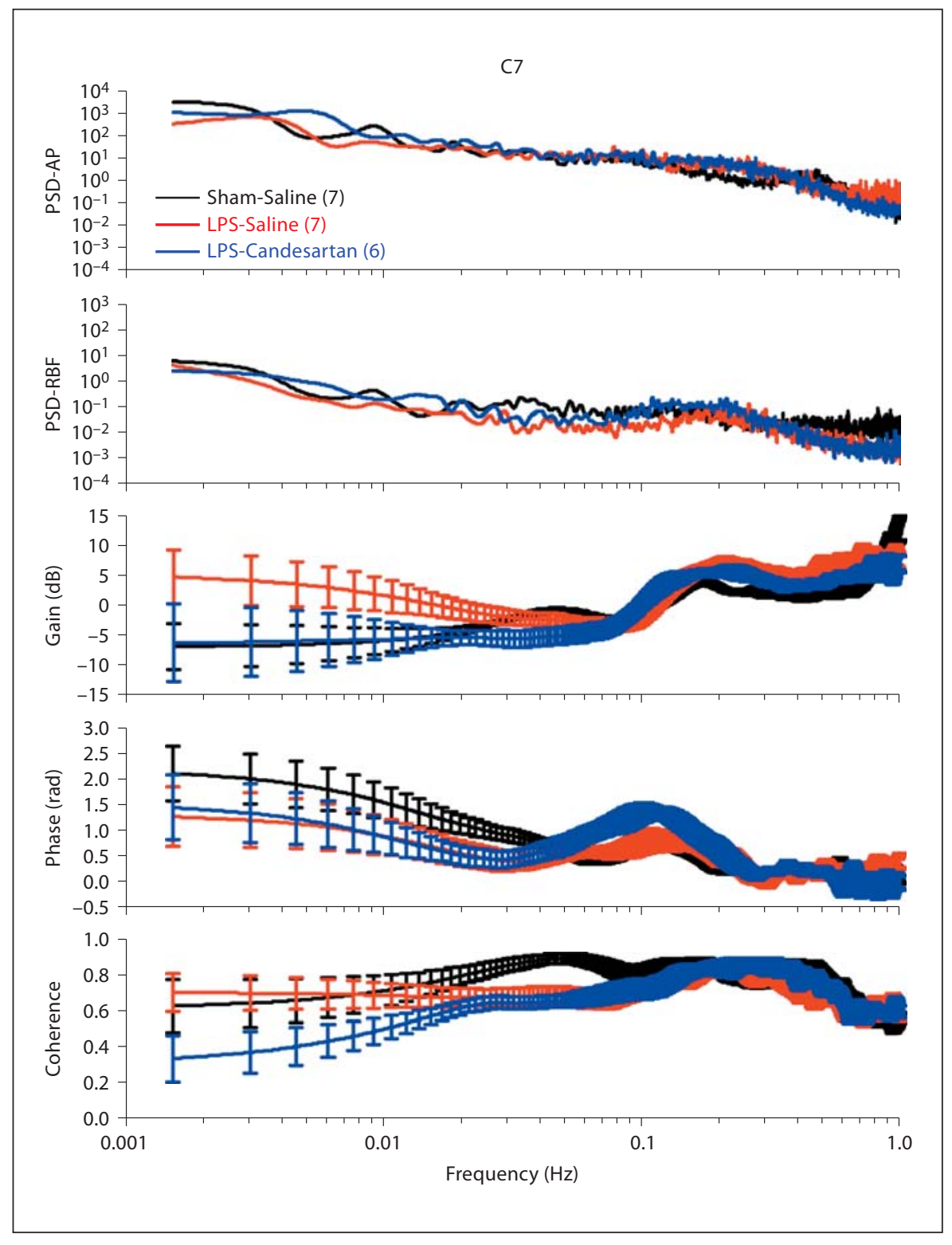

that produce tonic renal vasoconstriction, as in the spontaneously hypertensive rat, may impair dynamic autoregulation of $\mathrm{RBF}$ in the frequency range of both the MR and TGF and that renal denervation improves dynamic RBF autoregulation [23]. Several studies have documented that Ang II is an important modulator of the TGF by augmenting TGF sensitivity $[10,11]$. In view of these findings it might seem contradictory that candesartan restored the TGF response in endotoxemic rats. However, although RSNA was not measured in the present study, a plausible mechanism by which candesartan improved the TGF component of dynamic RBF autoregulation could be by reducing RSNA either via a central or peripheral action [24].

The contribution of the MR to the autoregulatory capacity of RBF during endotoxemia has, to our knowledge, not previously been evaluated. It is conceivable that an activation of the RAS and increased RSNA during endotoxemia could, by causing pronounced vasoconstriction of preglomerular arterioles, modulate the MR. Indeed, in the current study, candesartan caused renal vasodilatation, presumably mainly by direct antagonism of $\mathrm{AT}_{1}$ receptors on vascular smooth muscle cells of renal arterioles. However, throughout the experiment we observed, 
in all study groups, the signature of an intact MR of RBF autoregulation, characterized by an abrupt decrease in TF gain, with a transition from positive to negative $d B$ values, in the frequency range of $0.1-0.3 \mathrm{~Hz}$, associated with a positive phase peak. Thus, we found no significant effect of endotoxin, or candesartan, on the MR. These results indicate that during endotoxemia the renal MR is intact and not modulated by Ang II via $\mathrm{AT}_{1}$ receptors. Our observations are in agreement with previous results showing that Ang II does not influence the renal MR in healthy animals [17, 25-27]. However, other investigators [12] have found in the in vitro perfused hydronephrotic rat kidney a significant role for Ang II in the modulation of myogenic autoregulation. In addition, previous studies using TF analysis have shown that Ang II may enhance both the TGF $[17,28]$ and MR $[28]$. The discrepancy between those results and the observations in the present study could presumably be explained by differences in the experimental models. For instance, the experiments by Just et al. [28] were performed in conscious dogs and plasma Ang II concentrations as well as RSNA were likely within the physiological range. However, the endotoxemia model used in the present study is characterized by a highly activated RAS, a marked increase in RSNA $[1,3$, 29] and a low urine output.

Candesartan improved RBF autoregulation at frequencies $<0.01 \mathrm{~Hz}$ where the maximum autoregulatory efficiency is reached due to the combined action of both the TGF and the MR [9]. However, this improvement had a different time course than the effect on the TGF mechanism. At frequencies $<0.01 \mathrm{~Hz}$, candesartan produced a transient decrease in TF gain values in periods $\mathrm{C} 5-6$ that was not sustained during periods $\mathrm{C} 7-8$ in which candesartan normalized TF gain values in the TGF frequency range $0.01-0.03 \mathrm{~Hz}$. This could be explained by the fact that the MR contributes about $50 \%$ and the TGF mechanism about $35-50 \%$ of the complete dynamic autoregulatory response at frequencies $<0.01 \mathrm{~Hz}$ and that Ang II does not affect the relative contributions of MR and TGF to the total autoregulatory strength [9]. In the present study, candesartan rapidly increased RBF in endotoxemic rats while the effect on the TGF response was delayed and not evident until 80 min after drug administration. The mechanisms behind this time delay remains to be elucidated but may be explained by the different physiological properties of these two effects. Presumably, the rapid renal vasodilatory effect of candesartan was mediated through a direct action on vascular smooth muscle cells. On the contrary, the TGF response is a considerably more complex process dependent on tubular reabsorp- tion and flow rate, MD sensing, intracellular signaling processes and finally an effector action. Thus, it is reasonable to presume that the effect of candesartan on the TGF response would be delayed in relation to the direct vascular effect.

In conclusion, $\mathrm{AT}_{1}$ receptor antagonism with candesartan in endotoxemic rats, in a dose that did not significantly influence MAP or GFR, increased RBF and ameliorated the adverse effects of LPS on the TGF component of RBF autoregulation. It is possible that candesartan's improvement of the TGF was at least partly related to an increase in distal $\mathrm{NaCl}$ delivery secondary to decreased Ang II-mediated proximal tubular sodium reabsorption. This would decrease renal oxygen consumption coupled to tubular sodium reabsorption and contribute together with the enhanced RBF to increased renal tissue oxygenation during endotoxemia. In fact, we have previously demonstrated that low-dose candesartan increases intrarenal tissue $\mathrm{pO}_{2}$ in this model of endotoxemia [13]. Thus, the $\mathrm{AT}_{1}$ receptor antagonist candesartan may exert renoprotective effects by attenuating abnormalities in the TGF response, and by improving RBF autoregulation and kidney tissue oxygenation, during endotoxemia.

\section{Acknowledgements}

The study was supported by the Gothenburg Medical Society, the Swedish Medical Society, the Swedish Association for Kidney Patients, the Magnus Bergvall Foundation, the Swedish HeartLung Foundation, the Royal Society of Arts and Sciences in Gothenburg, and Brit Wennerström's Research Foundation.

References

1 Schrier RW, Wang W: Acute renal failure and sepsis. N Engl J Med 2004;351:159-169.

2 Boffa JJ, Arendshorst WJ: Maintenance of renal vascular reactivity contributes to acute renal failure during endotoxemic shock. J Am Soc Nephrol 2005;16:117-124

-3 Wang W, Falk SA, Jittikanont S, Gengaro PE, Edelstein CL, Schrier RW: Protective effect of renal denervation on normotensive endotoxemia-induced acute renal failure in mice. Am J Physiol Renal Physiol 2002;283:F583F587.

4 Yamaguchi N, Jesmin S, Zaedi S, Shimojo N, Maeda S, Gando S, Koyama A, Miyauchi T: Time-dependent expression of renal vasoregulatory molecules in LPS-induced endotoxemia in rat. Peptides 2006;27:2258-2270.

5 Boldt J, Papsdorf M, Kumle B, Piper S, Hempelmann G: Influence of angiotensinconverting enzyme inhibitor enalaprilat on endothelial-derived substances in the critically ill. Crit Care Med 1998;26:1663-1670. 
6 Tarpey SB, Bennett T, Randall MD, Gardiner SM: Differential effects of endotoxaemia on pressor and vasoconstrictor actions of angiotensin II and arginine vasopressin in conscious rats. Br J Pharmacol 1998;123:13671374.

$\checkmark 7$ Bond RF: Peripheral vascular adrenergic depression during hypotension induced by $E$. coli endotoxin. Adv Shock Res 1983;9:157169.

$\checkmark 8$ Van Lambalgen AA, Bouriquet N, Casellas D: Effects of endotoxin on tone and pressure - responsiveness of preglomerular juxtamedullary vessels. Pflugers Arch 1996;432: 574-577.

$\checkmark 9$ Just A: Mechanisms of renal blood flow autoregulation: dynamics and contributions. Am J Physiol 2007;292:R1-R17.

10 Ploth DW, Roy RN: Renal and tubuloglomerular feedback effects of [Sar1,Ala8] angiotensin II in the rat. Am J Physiol 1982;242:F149F157.

-11 Mitchell KD, Navar LG: Enhanced tubuloglomerular feedback during peritubular infusions of angiotensins I and II. Am J Physiol 1988;255:F383-F390.

$\checkmark 12$ Kirton CA, Loutzenhiser R: Alterations in basal protein kinase $\mathrm{C}$ activity modulate renal afferent arteriolar myogenic reactivity. Am J Physiol 1998;275:H467-H475.

-13 Nitescu N, Grimberg E, Guron G: Low-dose candesartan improves renal blood flow and kidney oxygen tension in rats with endotoxin-induced acute kidney dysfunction. Shock 2008;30:166-172.
14 Peirce B: Criterion for the rejection of doubtful observations. Astronomical J 1852;2:161163.

15 Cervenka L, Wang CT, Navar LG: Effects of acute AT1 receptor blockade by candesartan on arterial pressure and renal function in rats. Am J Physiol 1998;274:F940-F945.

16 Guron G, Marcussen N, Nilsson A, Sundelin B, Friberg P: Postnatal time frame for renal vulnerability to enalapril in rats. J Am Soc Nephrol 1999;10:1550-1560.

17 DiBona GF, Sawin LL: Effect of endogenous angiotensin II on the frequency response of the renal vasculature. Am J Physiol Renal Physiol 2004;287:F1171-F1178.

18 DiBona GF: Dynamic analysis of patterns of renal sympathetic nerve activity: implications for renal function. Exp Physiol 2005 90:159-161.

19 Wang H, Garvin JL, Carretero OA: Angiotensin II enhances tubuloglomerular feedback via luminal AT-1 receptors on the macula densa. Kidney Int 2001;60:1851-1857.

20 Kovacs G, Peti-Peterdi J, Rosivall L, Bell PD: Angiotensin II directly stimulates macula densa Na-2Cl-K cotransport via apical $\mathrm{AT}_{1}$ receptors. Am J Physiol Renal Physiol 2002; 282:F301-F306.

21 Kovacs G, Komlosi P, Fuson A, Peti-Peterdi J, Rosivall L, Bell PD: Neuronal nitric oxide synthase: its role and regulation in macula densa cells. J Am Soc Nephrol 2003;14:24752483.

22 Wang W, Jittikanont S, Falk SA, Li P, Feng L, Gengaro PE, Poole BD, Bowler RP, Day BJ, Crapo JD, Schrier RW: Interaction among nitric oxide, reactive oxygen species, and antioxidants during endotoxemia-related acute renal failure. Am J Physiol Renal Physiol 2003;284:F532-F537.
23 DiBona GF, Sawin LL: Effect of renal denervation on dynamic autoregulation of renal blood flow. Am J Physiol Renal Physiol 2004; 286:F1209-F1218.

24 DiBona GF, Jones SY, Sawin LL: Effect of endogenous angiotensin II on renal nerve activity and its arterial baroreflex regulation. Am J Physiol 1996;271:R361-R367.

25 He J, Marsh DJ: Effect of captopril on fluctuations of blood pressure and renal blood flow in rats. Am J Physiol 1993;264:F37-F44.

26 Just A, Arendshorst WJ: Nitric oxide blunts myogenic autoregulation in rat renal but not skeletal muscle circulation via tubuloglomerular feedback. J Physiol 2005;569:959974.

27 Arendshorst WJ, Brannstrom K, Ruan X: Actions of angiotensin II on the renal microvasculature. J Am Soc Nephrol 1999;10 (suppl 11):S149-S161.

28 Just A, Ehmke H, Wittmann U, Kirchheim HR: Role of angiotensin II in dynamic renal blood flow autoregulation of the conscious dog. J Physiol 2002;538:167-177.

29 Gupta A, Rhodes GJ, Berg DT, Gerlitz B, Molitoris BA, Grinnell BW: Activated protein C ameliorates LPS-induced acute kidney injury and downregulates renal INOS and angiotensin-2. Am J Physiol Renal Physiol 2007; 293:F245-F254. 